\title{
INTRODUCCIÓN AL GÉNERO LÍRICO COREANO "SICHO (시조)"*
}

Hye-jeoung KIM

Universidad de Salamanca

\section{El origen del sicho y el confucianismo}

in lugar a dudas, el pueblo coreano es amante de los versos, pues cabe recordar que este género lírico, el sicho ${ }^{1}$, fue parte integrante de un acontecimiento histórico en el que sus breves versos se utilizaron como medio de comunicación. Nos referimos al desenlace de la dinastía Koryo y a la fundación de la dinastía Choson. Los insurgentes contra el monarca de Koryo, encabezados por la saga Yi, que fundaría después el nuevo reino, intentaron reunir el mayor número posible de participantes en la subversión, y pusieron en marcha un contacto discreto con los que les interesaba persuadir. En realidad, esta conspiración contra el trono de Koryo era por entonces un secreto a voces.

En los entresijos de momentos críticos y tensos, la vida de los implicados, por activa o por pasiva, estaba en peligro, pues una respuesta negativa a la colaboración por su parte significaba su propia sentencia de muerte.

El primogénito del fundador de la Dinastía Choson, Yi Bang-won (1367-1422), el tercer rey de la dinastía Choson, quería involucrar a los altos funcionarios de la corte, y propuso un encuentro a Chong Mong-chu (1337-1392), integrante del núcleo del poder político del reino Koryo y, a la vez, académico de renombre, para tantear la posibilidad de establecer con él una alianza de propósito subversivo.

\footnotetext{
* Este artículo corresponde a un proyecto de investigación financiado por el Instituto de Traducción de Literatura Coreana.

${ }^{1}$ El término "sicho" es la trascripción fonética castellana de la orginaria voz coreana. Por tanto, existen otras formas de verter el vocablo: por ejemplo, en el ámbito de habla inglesa se utiliza a menudo la palabra, "sijo" y/o "shijo".
} 
El ambicioso Yi le remite así un mensaje sugerente en forma de tres versos del sicho, persuadiéndole para que se una con él en la conspiración contra el rey:

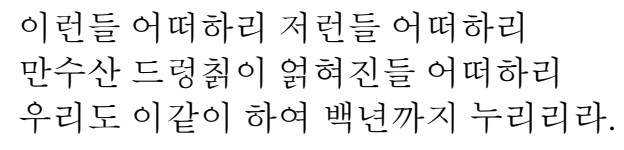

Qué más da, que sea de una manera o de otra.

Qué importa, por muy enredadas que estén las arrurruces en el monte Mansu²

Bien aliados, nosotros también gozaremos de cien años de vida. ${ }^{3}$

Chong Mong-chu, muy consciente de la circunstancia de que cualquier respuesta negativa a esta invitación podría provocar de inmediato su muerte, le contesta también con tres versos de sicho:

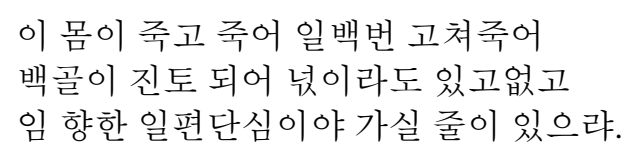

Morirá, morirá este cuerpo, y por cien veces que vuelva a morir, Serán polvo estos huesos albos, y el alma pervivirá o no.

Mas el rojo corazón íntegro hacia mi amado ha de persistir.

Estos versos de Chong Mong-chu se anticipan en casi 200 años al célebre verso «serán polvo, mas polvo enamorado» de Quevedo, profesando una fidelidad inquebrantable hacia su amado más allá de la muerte. Enfatizan así una lealtad invulnerable hacia su amado, obviamente el rey de Koryo en este contexto histórico, una de las virtudes más apreciadas por los confucianos. Chong fue asesinado en el camino a su casa el mismo día, tras su encuentro con Yi Bang-won. Sin embargo, fue muy respetado en la posteridad por su integridad y lealtad, incluso durante el reino Choson, contra el que él se opuso con todas sus fuerzas, dado que el nuevo reino se construyó sobre las bases ideológicas del confucianismo. Por esta razón, Yi Song-guie (1335-1408), el fundador del reino Choson, ni persiguió ni eliminó a todos los súbditos que se mantuvieron fieles a la corte anterior ${ }^{4}$. Surgidos estos nuevos nobles del Sadebu a finales del reino Koryo, dirigieron y culminaron la insurrección, y derrocaron

\footnotetext{
${ }^{2}$ Mansu: significa diez mil años de vida, o una vida eterna; sólo se podía utilizar refiriéndose a la vida de los emperadores. Por tanto, estos versos tienen dos caras: es decir, su autor por un lado está engatusando al otro para que éste se posicione a su favor y, por otro, le amenaza en caso de que no colabore con él para apoderarse del trono, lo que insinúa mediante los términos "Mansu" o "cien años de vida".

${ }^{3}$ Cien años de vida: se refería a la existencia longeva, utilizándose, en general, para la vida de los reyes. Por tanto, connota una vida lujosa a la altura de los monarcas.

${ }^{4}$ El fundador del reino Choson hizo una política muy flexible y fue generoso con los rebeldes que, en la mayoría de los casos, eran funcionarios del reino anterior o con los académicos honrados que no querían incorporarse a la nueva corte. Se retiraron a la naturaleza, por lo que se inicia un nuevo tipo de sicho, el de la vida apartada en la naturaleza, lejos de la sociedad.
} 
finalmente el reino Koryo. Eran las mismas personas que iniciaron un nuevo género lírico, el sicho, y la importancia del confucianismo como fuerza disuasoria de los nobles del Sadebu fue primordial para el nuevo orden social. Por esta razón, el sicho adquiere una de las características que lo distinguen de los demás poemas cortos de Asia Oriental $^{5}$ : si bien el sicho coreano, la danka china y el jaiku japonés comparten un punto común, el haber derivado de los cantares-poemas cortos llamados "danka (단가)", , los versos del sicho están modulados por los pensamientos confucianos desde su origen, claramente fuera del ámbito budista o taoísta. Es preciso tener en cuenta que éstos permiten la introducción oportuna de sensaciones alusivas e instantáneas, y que se adaptan a la secuencia de los versos breves del sicho o del jaiku por su propia corta extensión. Aun cuando el carácter espontáneo, muy apreciado en los poemas cortos, no se acomodaba demasiado bien a la frecuente función didáctica del sicho, este género compensaba su brevedad ofreciendo una profunda reflexión filosófica sobre la vida y el propio ser humano en su corto desarrollo.

Hasta que se introdujeron y se aceptaron las pautas socio-políticas proporcionadas por el confucianismo y el neo-confucianismo (a partir de la era del reino Song en China), el budismo sirvió de mentor espiritual por el que se regía la sociedad coreana. Sin embargo, el budismo sufrió un rechazo radical por el nuevo trono del reino Choson, dada su extremada corrupción y degeneración en la práctica, y fue descartado para corregir las perversiones de la conducta social. Por tanto, las temáticas de los versos del sicho giran exclusivamente en torno a las enseñanzas de Confucio para realzar las éticas humanistas, que postulan la lealtad y la fidelidad, extendidas al amor filial y al servicio al bien común de la sociedad. Estas doctrinas fueron utilizadas eficazmente para establecer un nuevo orden social.

En tal contexto histórico, resulta imprescindible ahondar el conocimiento sobre los nuevos nobles del Sadebu, que lograron el cambio socio-político mediante la construcción de un nuevo reino, apoyado en la ideología confuciana, además de pergeñar un nuevo género lírico, el sicho.

A finales del reino Koryo, se formó una nueva clase social de "letrados o funcionarios académicos", paralelos a los aristócratas tradicionales de las grandes estirpes. En contraste con éstos, los nuevos nobles alcanzaron los altos cargos merced a su propio esfuerzo académico tras haber aprobado los exámenes oficiales de las

\footnotetext{
${ }^{5}$ Tanto el confucianismo como el neoconfucianismo, a partir de la era Song china, sirvieron de suelo ideológico en el que prosperó la composición de los versos de sicho. Si el jaiku se centra más en los sentimientos o las sensaciones espontáneos de tono budista zen o taoísta, la característica reflexiva y humanista del confucianismo confiere al sicho su idiosincrasia en el campo de los versos cortos a lo largo del desarrollo de la literatura de Asia Oriental.

${ }^{6}$ Véase Pai (1965: 23-24).
} 
oposiciones. En consecuencia, dichos nobles acaban formando un círculo de élite constituido por intelectuales muy competentes. Mientras que la nobleza heredada gracias al linaje familiar era patrimonio de unos cuantos privilegiados, los nuevos nobles iban consolidando un terreno político en que podían enfrentarse a la presión de los antiguos nobles. Al principio, los reyes de Koryo adoptaron un inédito sistema político en la corte en función de la nueva nobleza destinada a centrar el poder y a librarse de la intervención política de los aristócratas tradicionales, pero irónicamente fue la neoaristocracia la que derribó el reino Koryo. La formación académica de estos letrados se llevó a cabo en el aprendizaje cabal de las doctrinas de Confucio ${ }^{7}$. Teniendo en cuenta que Confucio fue un aspirante a un cargo de gobernador en su época, por lo que deambulaba de un reino a otro, ofreciendo su sistema administrativo para regir un estado, su enseñanza era la más indicada para prepararse antes de emprender la carrera de funcionario. En consecuencia, empezaron a soñar con fundar un reino basado en la ideología confuciana. Además, consideraban necesario un orden social distinto para quienes se educaron en tales doctrinas que les permitieran ocupar una posición más cómoda en la sociedad. Y definitivamente se convirtieron en los principales colaboradores-colaboracionistas en favor de implantar un nuevo reino.

Los nuevos nobles poseían un alto nivel de conocimientos sobre las obras literarias de los escritores más importantes de la historia, tal como fue exigido en los exámenes de las oposiciones, y eran potencialmente literatos muy disciplinados. Por tanto, no era de extrañar que ellos forjaran un género literario a su altura.

\section{El sicho de Sadebu ${ }^{8}$}

Los versos del sicho, en sus primeras andaduras, reflejan la realidad social y el ámbito filosófico de la época. Si bien continúan teniendo un sesgo metafísico, a partir del reino Choson adquieren un carácter didáctico, pues los nuevos nobles, ahora dirigentes de la nueva dinastía, sienten la necesidad de dar a conocer las doctrinas confucianas y de educar al pueblo de manera eficaz. Los cantares del sicho eran un medio de comunicación ideal para la población, carente de estudios académicos.

Pero no todos los letrados pertenecientes al Sadebu eran colaboradores del nuevo reino; es decir, éste estaba dividido en dos bandos. En el bando de los no colaboradores se encontraban los súbditos del reino Koryo, que preferían abstenerse de su vida sociopolítica para salvaguardar el honor personal y lealtad a su rey; o aquellos que no aceptaron el cambio de realidad y que quisieron retirarse en lugares recónditos, lejos del

\footnotetext{
${ }^{7}$ La formación del Sadebu y su estrecha relación con el confucianismo está detalladamente relatadas en Kwon - Kim (1997: 344-348).

${ }^{8}$ Véase un estudio monográfico sobre el sicho de Sadebu en Shin (1997).
} 
mundo y de la actualidad política tornándose por su propia voluntad en desterrados contrarios al nuevo reino. En consecuencia, las temáticas del sicho varían notablemente a medida que se acentúan las discrepancias entre los dos bandos $\mathrm{y}$, a la vez, a medida que va fortaleciéndose el poder de los nuevos nobles del Sadebu. En este proceso, el sicho cobra también con más decisión su cuerpo poético.

Los versos de Pak In-ro (1561-1642) son muy conocidos entre los del sicho de Sadebu. Tanto el tema muy confuciano en torno al amor filial como las referencias expuestas que demuestran su buen conocimiento de la historia y la cultura chinas son los componentes que abundan en la poesía de Sadebu.

반중 조홍감이 고와도 보이나다

유자 아니라도 품음직도 하다마는

품어 가 반길 이 없을새 글로 설워 하나이다.

¡Qué hermoso el temprano kaki rojo en la bandeja!

Aunque no sea mandarina, apetece llevarlo oculto en el pecho.

Mas lamento que no haya quien se regocije con el kaki que llevo (Hwang - Filinich, eds., 2005: 38-39). ${ }^{9}$

\section{El sicho de las damiselas guiseng (기생) ${ }^{10}$}

La participación de las damiselas guiseng como autores femeninos de sicho dio frescura y vitalidad al panorama rutinario de este género lírico. La sensibilidad femenina, plasmada delicadamente en los versos, contribuyó a que se ampliara el terreno temático del cultivo del sicho, restringido hasta entonces a la metafísica e ideología de los varones intelectuales, y limitado por la exclusividad del círculo cerrado de letrados que componía sicho. Empiezan a expresarse a través del sicho sentimientos melancólicos de tinte romántico. De manera directa o sugerente los versos se atreven a cantar el amor corporal de las parejas, el dolor de la separación, la melancolía o la añoranza. En pocas palabras, exteriorizaron las experiencias íntimas y particulares.

Debido a la peculiaridad del oficio de guiseng, los temas centrales del sicho compuesto por este grupo de mujeres implican en general, como hemos dicho, el amor sentimental, el dolor y la tristeza de las despedidas o la melancolía. Los versos se tiñen cada vez más de sentimientos íntimos o de pensamientos personales -en contraste con la

\footnotetext{
${ }^{9}$ El poeta expresa una de las cinco virtudes más importantes en la sociedad confuciana: el amor filial. Cuando Pak visitó a su amigo, le sirvió el pérsimo (kaki) rojo. Al ver la preciosa fruta, recordó un episodio antiguo de China: un buen hijo se llevó ocultas en su pecho unas mandarinas que le sirvieron para dárselas a su madre. Pero el poeta coreano ya no tiene a sus padres a quienes pueda regalar.

${ }^{10}$ Las mujeres que entretenían a los barones aristócratas aprendían como base de su arte para seducir a los hombres diferentes habilidades artísticas como el canto, el baile, la pintura, la práctica de la caligrafía. Sobre todo, se apreciaba mucho la capacidad de componer los versos para comunicarse con sus clientes. Por tanto, la mayor parte de los versos escritos por mujeres, conocidos y transmitidos hasta la actualidad, son obras de esas mujeres llamadas guiseng, cuya imagen se equipara a la de las geisha japonesas.
} 
mentalidad colectiva basada en el confucianismo del principio-, y los amoríos o el patetismo se tornan en una expresión de perversión y de libertinaje equiparable al sokyo de Koryo.

Entre las mujeres que ejercían este oficio de guiseng, sobresale una dama llamada Juanchini (1511-1541). Su extraordinaria sensibilidad lírica y su capacidad intelectual le permitieron elaborar versos de excelente calidad. Las suyas pertenecen a las mejores obras compuestas en forma de sicho. Además de su arte para interpretar música y para bailar todo tipo de danzas, tan sublimes fueron sus poemas cantados que la hermosa Juanchini llegó a ser considerada como uno de los tres tesoros de la ciudad de Songdo, junto con el ilustre académico So Kiong-dok y la famosa cascada Backyon de la región.

Sin lugar a dudas, los versos de esta poetisa que citamos abajo representan sobradamente la poesía guiseng. Destacan no sólo la sutileza de la sensibilidad femenina, sino también la originalidad poética debida a la imaginación exquisita de esta autora. El poema transmite la soledad aún más marcada por la larga noche de invierno y su deseo de prolongar el tiempo de la noche que pasa con su amado.

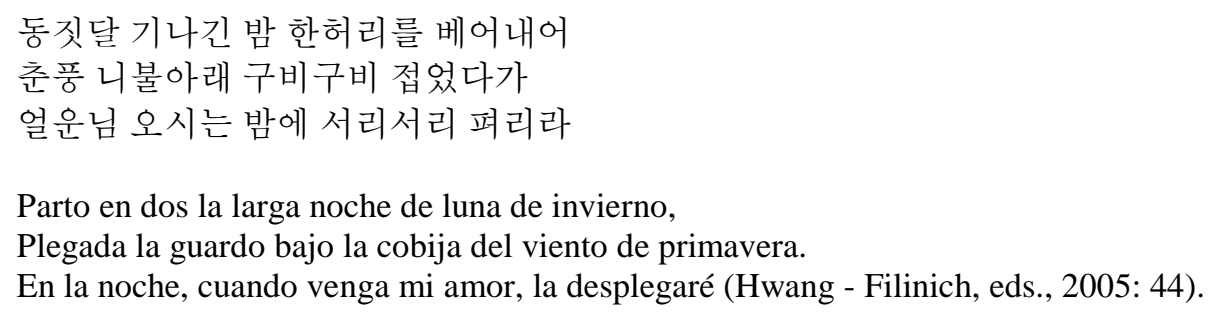

\section{La estructura poética del sicho}

El término "sicho" es la abreviatura del original sicholgacho (시절가요), que significa 'los cantares del momento' ${ }^{11}$. Por tanto, el propio nombre del género apunta a su naturaleza como canción. Sus versos se escribían para ser cantados, aunque a día de hoy se ha perdido la tradición de entonarlos.

Es importante destacar, sobre todo, que este género lírico fue sustituyendo al hansi, poemas cultivados originalmente en China. A diferencia del danka, procedente del hansi (poesía escrita en caracteres chinos y con formas adaptadas de los poemas chinos), que se compone en cuarteto, la estructura del sicho se construye a base del terceto, y sus tres versos están estructurados en forma de "objeto-relación-sentido":

\footnotetext{
11 «The first use of the term sijo occurs in a record written by Sin Kwang-su (1712-1775) which states that the sijo chang (song) began with Yi Se-chun, a well known contemporary singer. This reference is to the music rather than to the lyric and the term itself seems to be a shortened version of sijolgajo, meaning popular seasonal songs» (O'Rourke, 1987: 1).
} 
El sicho está estructurado en forma de un triángulo de "object-relation-meaning" del sistema ORM según el análisis, desde la óptica de la literatura clásica coreana, realizado por primera vez por Kim Dejeng. En el primer verso introduce el objeto, y en el segundo lo relaciona con los demás para llegar al tema y, a su vez, manifiesta más en detalle el propósito de haber introducido el objeto y, finalmente, en el tercero revela el sentido del objeto para el propio autor. De esta manera, el sicho demuestra el proceso de concebir la realidad del mundo. Esta estructura se corresponde con un proceso muy común y natural a la hora de reflexionar y de ponerse a escribir sobre un tema (Kim, 2005: 243). ${ }^{12}$

En el inicio de la formación del sicho, los poemas fueron compuestos para ser cantados, como hemos dicho, ya que estos versos tradicionales en general se acompañaban de diferentes tipos de música o de melodía, ambas ayudando a memorizar los versos. Pero en el proceso de transcribir y recopilar todos aquellos versos en los cancioneros la parte musical desaparece paulatinamente pese a que fue registrada en partituras. Quizá ya no se precisaba la música para aprender de memoria las letras, puesto que la gente no acudiría a su propia memoria para recordar los versos si tenía a su disposición las letras recogidas por escrito.

La relación con la música es una de las características principales del sicho, por lo que se postula la teoría de que el sicho procede de la poesía tradicional de Koryo, llamada "sokyo" debido además a que la distribución silábica de 3-4-3-4 del sicho coincide con la del sokyo. Sin embargo, esta combinación silábica de 3-4-3-4 y sus variaciones se encuentran también en las canciones populares denominadas "minyo (민요)". En este sentido, puede que el núcleo de la base estructural de 3-4 sílabas sea la forma más conveniente para crear un ritmo poético en coreano, tal como los versos de octosílabo se adaptan bien al español.

En relación a la temática, destacan el sicho de Sadebu, el de guiseng, representados respectivamente por versos de pensamiento metafísico y de sentimientos de amor y de melancolía. Además, hay versos que reflejan la vida cotidiana, compuestos por gente corriente que no pertenecía a ningún grupo social determinado, y llamados sicho del pueblo. En este sentido, la exclusividad del Sadebu en relación con la composición de los versos del sicho va cediendo hasta extenderse a todas las clases sociales. En consecuencia, el sicho manifiesta la sensibilidad lírica de todo el pueblo coreano, sobre todo desde que los versos del sicho pasaron a transmitirse a través de la memoria colectiva en la tradición oral.

\footnotetext{
12 «시조의 의미구조를 전통적인 글쓰기 발상과 연결하여 문학 교육적 관점에서 '대상 object관계relation-의미 meaning의 ORM구조로 접근한 연구자는 김대행이다. 그는 '초장에서 대상을 먼저 제시하고, 중장에서 그것을 다른 것들과의 관계 속에 놓음으로써 그 속성을 구체화하고, 종장에서 주체인 나에 게 주는 의미를 규정하는 절차를 보이는 사고 과정은 시조뿐만 아니라, 說을 비롯한 거의 모든 글쓰기에 두루 나타나는 전통성과 보편성을 가진 구조로 파악하였다».
} 
En relación a la forma, descubrimos tres tipos de sicho, cuya clasificación se basa en general en la distribución silábica de $\operatorname{los} \operatorname{versos}^{13}$ :

- Piongsicho (평시조): versos sencillos en tercetos de menos de 45 sílabas en total, y sus infinitas variaciones de distribución silábica a base de 3-4, como 3-4-3-4/ 3-4-4-4/ 3-4-4-3, etc.

- Yonsicho (연시조) u otsicho (엇시조): terceto con una variación: se permite un verso dilatado sin límite entre el primero y el segundo.

- Sasolsicho (사설시조): extensión del número de tercetos de piongsicho hasta convertirlos en un poema largo.

La propagación rápida y asidua de este género lírico se debe a su forma sencilla y flexible, relativamente libre del rigor de la forma prefijada de los versos hansi. Los versos del sicho son los que más se han transmitido hasta la actualidad comparados con otros tipos de versos, y su gran mayoría pertenecen al sicho de Sadebu. En el siglo XVI, cuando la composición del sicho se extendió a otras clases sociales, surgió el oficio de los "cantantes" profesionales que entretenían a los aristócratas con sus cantares-verso del sicho. En este proceso, se crearon diferentes compañías de cantantes. Y, lógicamente, en tal contexto histórico aumenta la necesidad de transcribir y recopilar más versos del sicho destinados a las actuaciones. Por tanto, la elaboración del primer cancionero del sicho está estrechamente vinculada con esta faceta musical de los versos. No se sabe si se componían primero los versos o si, a la inversa, las canciones requerían las letras. Lo obvio es que la música formaba parte de la esencia de los versos del sicho, contribuyendo a que se confeccionaran los cancioneros gracias a los cuales conocemos hoy en día la mayoría de los versos que de otro modo podrían haber quedado enterrados sólo en la memoria del pueblo.

\section{Los cancioneros del sicho}

En parte, la creación del alfabeto coreano hangul en 1446 influyó en que se cambiaran las modalidades del sicho. Sus versos concebidos originalmente de forma oral y cantada ${ }^{14}$, pasaron a ser registrados en grafías, sobre todo en escrituras propias del

\footnotetext{
${ }^{13}$ El método para clasificar los tipos de sicho está sujeto a variaciones, si bien la clasificación más aceptada es la que indicamos en el texto.

${ }^{14}$ «El sicho se transmitía en las letras de canciones [...] y todos los nombres que se refieren a este género lírico están relacionados estrechamente con música» (Byon, 1989: 11): «시조는 원 래 음악의 노랫말로 전승되어 왔기 때문에 시조를 가리키는 명칭들도 음악과 깊은 관련을 가지고 있다.... 모두 악곡과 깊은 관련이 있다».
} 
coreano. Este hecho contribuyó a que el pueblo cobrase su identidad a través del proceso de alfabetización de los versos del sicho:

En un momento dominado por la cultura china, la aparición de los cantares del sicho, autóctonos de la propia cultura coreana, hace hincapié en la mentalidad colectiva del pueblo coreano. En consecuencia, resalta la diferencia entre Corea y China en relación con la música, la canción y, sobre todo, la lengua. El sicho fue cultivado y cuidado con la conciencia de estar valorando lo más nuestro del pueblo, y eso aumentó su auto-estima (Cho, 1994: 216-217). ${ }^{15}$

El sicho empieza a tomar su forma a finales del siglo XIV, más o menos en la misma época en que evolucionan los romances o canciones españoles ${ }^{16}$, a medida que el castellano iba forjando un sistema lingüístico a partir del latín vulgar. La carencia de alfabeto propio hasta entonces obligó a depender de la memoria colectiva del pueblo, y el nacimiento de los cancioneros está endeudado con aquélla. En este sentido, los cancioneros españoles se pueden equiparar con los del sicho. En las antologías del sicho se hallan recopilados los versos con sus respectivas partituras, tal como apreciamos también en los cancioneros españoles. Obviamente, no sería del todo acertado comparar los cancioneros-antología de sicho con los cancioneros españoles, aunque compartan la misma esencia: en ambos casos se pueden confirmar versos cantados, transmitidos por la tradición oral y recogidos con sus partituras en las antologías; versos que, mejor que cualquier otro medio, transmitían la sensibilidad lírica de un pueblo, tal como fue concebido por Antonio Machado y Álvarez, "Demófilo":

Un romancero es más útil, en cuanto muestra mejor el carácter de una nacionalidad y el de sus héroes; un cancionero vale infinitamente más para el psicólogo, porque revela al pueblo como persona en la Humanidad, e indica las ideas que en común posee con todos los otros de la tierra, sin relación a tiempo ni espacio, descubriendo también las particularidades del individuo, muchas veces oculto, pero nunca perdido en esta riquísima manifestación del espíritu popular, no en hechos determinados como en los romances, sí en pensamientos, sentimiento y voluntades. ¿Queréis conocer la historia de un pueblo? Ved sus romances. ¿Aspiráis a saber de lo que es capaz? Estudiad sus cantares (Machado y Álvarez, 1869).

Este texto resume la esencia del valor literario de los versos tradicionales no sólo españoles, sino también coreanos, que se transmitieron de generación en generación en forma de cantares. Ciertamente la ideología y la emocionalidad de un pueblo subyacen en esos versos, ambas conectadas con el fundamento de la humanidad en el plano individual y, a su vez, universal.

${ }^{15}$ «시조의 문학사적 가치로 가장 두드러진 것은 민족 주체성의 측면이다. 한문 문화가 중심에 자리 잡고 있던 시기에 우리말로 노래하는 시가 형식이 창안되었다는 것은 주목할 만하다. 시조가 우리말로 되어 있다는 사실은 중국의 음악과 우리 음악은 다르며, 그러기에 그 노래말은 철저히 우리말로 되어 있어야 한다는 자각이 깔려 있다. 이러한 자각 아래서 그 양식이 전아하게 다듬어지고 많은 사람들에 게 향유된 양식이었다는 측면에서 더 한층 가치가 높아진다».

${ }^{16}$ Véase Cho (2000a, y 2000b: 207-219). 


\section{Bibliografía}

BYON, Chong-hyun (1989): 주해 시조 가사 강독(Lectura e interpretación del sicho). Kiongnam, Universidad de Kiongnam.

CHO, Dong-il (1994): 한국문 학강의(Estudios de literatura coreana). Seúl, Kilbot. (2000a): Introduccón a la literatura coreana. Lima, Pontificia Universidad Católica del Perú.

(2000b): Historia de la literatura coreana. Lima, Pontificia Universidad Católica del Perú.

HWANG, Tae-jin - FILINICH, María Isabel, eds. (2005): Aroma del Este: Antología de la poesía clásica coreana sijo, México, El Colegio de México.

KIM, Chehyon (1975): 시조 문학론 (Un estudio sobre la literatura del sicho). Seúl, Yojonsa.

KIM, Duck-hyun (2005): 시조문학 교육론 (La metodología didáctica del sicho). Seúl, Packichong.

KWON, Tuwhan - KIM, Hak-song (1997): 고전시가론 (Estudios sobre el sicho clásico). Seúl, Saemunsa.

MACHADO Y ÁLVAREZ, Antonio (1869): “Apuntes para un artículo literario. Introducción al estudio de las canciones populares", Revista Mensual de Filosofía, Literatura y Ciencia, 1, pp. 173-179.

O’ROURKE, Kevin (1987): The Sijo Tradition. Seúl, Jongeumsa.

- ed. (2002): The Book of Korean Sijo. Cambridge, Harvard University Press.

PAI, Inez Kong (1965): The Ever White Mountain: Korean lyrics in the classical sijo form. Tokio, John Weatherhill.

SHIN, Youn-woo (1997): 조선조 사대부 시조문학 연구 (Estudios del sicho de Sadebu en el reino Choson). Seúl, Packyijong. 